\title{
Erratum to: Enthesitis in seronegative spondyloarthropathies with special attention to the knee joint by MRI: a step forward toward understanding disease pathogenesis
}

Ragab Yasser • Emad Yasser • Darweesh Hanan •

El Shaarawy Nashwa • Johannes J. Rasker

Published online: 28 January 2011

(C) Clinical Rheumatology 2011

\section{Erratum to: Clin Rheumatol \\ DOI 10.1007/s10067-010-1655-4}

In the original publication, the list of authors in the author group should have included Dr. El Shaarawy Nashwa.

The online version of the original article can be found at http://dx.doi. org/10.1007/s10067-010-1655-4.

R. Yasser

Radiology Department, Faculty of Medicine, Cairo University,

Cairo, Egypt

R. Yasser $\cdot$ E. Yasser

Dr Erfan and Bagedo General Hospital,

Jeddah, Saudi Arabia

E. Yasser $(\bowtie) \cdot$ D. Hanan

Rheumatology and Rehabilitation Department,

Faculty of Medicine, Cairo University,

Cairo, Egypt

e-mail: yasseremad68@yahoo.com

\section{E. S. Nashwa}

Rheumatology and Rehabilitation Department,

Suez Canal University,

Ismailia, Egypt

\section{J. J. Rasker}

University of Twente,

Enschede, The Netherlands 